\title{
Environmental Degradability of Nigerian Long Bamboo Fibre-Reinforced Polymer Composite (NLBFRPC)
}

\author{
Friday A. Ovat
}

\begin{abstract}
There has been increased interest in the development of composite materials with relevant mechanical and chemical properties for use in industrial and domestic applications. Not much has been done in the area of their response to the practical environment that their applications are found. In this present study, the pest and chemical resistance of the Nigerian long bamboo fibre and reinforced composite on exposure to a practical environment with particular respect to the soil was investigated. Natural fibre has come up as materials that can be easily renewed, available and affordable replacement to man-made materials suchlike glass, carbon and aramid. They are used as reinforcements for composite development. The fibre (long bamboo fibre) was extracted using maceration method. The fabrication of the composite was carried out using Bisphenol-A-diglycidyl ether (BADGE) as the matrix and the long bamboo fibre as reinforcement. Tests were carried out to determine the effect of environment on the degradation of the composite and the long bamboo fibre. The composite showed significant resistance to pest infestation or attack while the long bamboo fibre showed susceptibility to the soil and its moisture condition thereby decomposing completely after a period of time. Therefore, the material developed can be used in aquatic craft applications with a strong dependence on its mechanical properties.
\end{abstract}

Index Terms-Nigeria, Bisphenol-A-diglycidyl ether, Longbamboo fibre, Natural fibre, Composite, Soil, Environment

\section{INTRODUCTION}

From early 1960's, there has been an expansion and request for materials that are rigid, stiffer, resistant to weather conditions and stronger needed in different fields as distinct as aerospace, energy, civil and mechanical constructions. The claim put on materials for superior across-the-board performance is so important and distinct to the extent that no one single material will assuage them. This limitation has resulted in the growth of the dateless notion of putting different materials in an integratecomposite form to achieve the user requirement, this mixedmaterial system results in an account that cannot be attained by the individual constituent which offers a great deal of advantages of a flexible design [2].

Nature is full of examples of composite materials. Wood for example is fibrous in nature and can be called a fibrous composite. Cellulose fibre can be found in wood and this cellulose fibre has high tensile strength even though it is elastic (i.e. low stiffness), the lignin matrix joins the fibres and provides stiffness. Bones are other examples of a natural composite which supports the weight carried by the human body and other animals. It comprises of short and soft

Published on June 21, 2017

F. A. Ovat is with Department of Mechanical Engineering, Cross River University of Technology, Calabar, Nigeria. (e-mail: fraijoe@yahoo.com) collagen fibres which is built in a mineral matrix called apatite [12].

Additional to naturally existing composites, there are also other engineering materials that are composite in general ways and have been used for a long time. Examples of these engineering materials include but not limited to Portland cement or asphalt mixed with sand, carbon black in rubber, and glass fibres in resin etc.

The different rates of urbanization demand the use of light weight and disposable materials which sufficiently increase the application of plastics-based output for different operations. The changes bring about new development in the minds of Scientists in developing materials that are eco-friendly with improved versions. Development of bio-composites, a shift that attracted global attention within a few years has given rise to considerable research interests due to increase in environmental menace created by petroleum based products. The use of traditional composites made up of glass, aramid, or carbon fibres has widely been investigated in the past few decades [16], [7], [9]. Extending these studies to renewable resources based natural fibre created newer methods that are environmentally friendly leading to low-cost alternatives for artificial fibres. Different natural fibres such as flax, pineapple, ramie, bamboo, jute, kenaf, henequen, and hemp have been investigated as reinforcing agents for polymer matrices by different researchers [8], [6], [13], [4], [11].

As advancement in technology continues to grow, the uses and applications of metallic and non-metallic alloys also become limited. Therefore there arose the need for corrosion resistant materials, low electrical and thermal conductivity or insulation materials, materials that can easily be joined, casted and formed into complex and intricate shapes including having wide range of choice of appearance, colour and transparencies although the disadvantages of this category of materials such as low strength, low useful temperature, less dimensional stability over a time-creep effect, aging effect as there harden and becomes brittle over time, sensitivity to environment, moisture and chemical, and poor machinability cannot also be undermined[10].

It becomes imperative to consider these materials as an alternative to metallic and non-metallic materials for the above reasons.

Again the limitation of these materials is seen from their disadvantages which have also brought about the modification. These materials are called plastics or polymers.

A composite is produced by putting together two or more materials having different properties combined together. Composites are also high load bearing materials that can be 
called reinforcement added in weaker materials that are called the matrix.

Generally, the properties of composite materials are conventional self-assertive in multifold when compared to those of the individual materials used.

Most times there are two constituents of a composite material, one is called the matrix and the other is the reinforcement. The basic function of the matrix is the conveyance of stresses from the supporting fibre/particle and to keep them away from mechanical and/or environmental harm as long as the presence of fibre or particles in a composite improves on their mechanical properties such as strength, stiffness etc. This is to take advantage of the superior properties of both materials without exposing the weakness of any. The matrix materials may be metallic, polymeric or ceramic. Polymer-matrix composite is so-called when a matrix is used as a polymer. The determination of the properties of polymeric composite materials is basically done by three elements such as the resin, the reinforcement and the interface between them which could be the filler [15].

Reinforcements provide rigidity and strength, assisting in reinforcing the structural loads. Matrix which could be organic or inorganic material keeps the position and orientation of the reinforcement in the composite. Constituents of the composite retain their individual physical and chemical properties significantly whereas together they combine to make up the qualities that one constituent cannot produce while alone. Reinforcements have been made of inorganics (synthetic fibre) such as glass, carbon and amid [3].

The result of increase in environmental awareness, rise in crude oil prices, challenges in global waste problems and increased processing cost brought about the innovational concept of sustaining and reconsidering renewable resources. Using natural fibres obtained from renewable resources as reinforcing fibres in both thermoplastic and thermosets matrix composites provides positive environmental benefits with respect to ultimate disposability and raw material utilization in industries [17].

Reinforcement from natural fibres used in the polymer has the following advantages; non-abrasive nature, availability, biodegradability, low energy consumption during processing and low cost. Again, they have low density and high specific properties. The peculiar properties of these fibres can be compared to the ones of traditional reinforcement. Some researchers have investigated the potentials of natural fibres for use as reinforcements in polymers.

The mechanical properties found in natural fibres such as bamboo, sisal, banana, vakka, were analysed and concluded that the bamboo fibres have good flexural and tensile properties than other fibres [10].

Bamboo, as natural fibres have been seen as a renewable and cheaper substitute for man-made fibres, example glass and carbon. They are used as reinforcement in making structural components and have high definite properties such as impact resistance stiffness, flexibility and modulus and can be equated to others like glass fibre.

Bamboo as a plant can be used as supporting material in the form of the whole bamboo, in sections, in strips and the fibres. Bamboo is used in different forms of applications, in low rise construction to resist earthquake and wind loads, bamboo mats composite in conjunction with wood for beams and shear wall in low-rise construction. Bamboo fibre can be used as reinforcement with various thermoplastic and thermoset polymer [5]. Reinforced composites find their applications in several fields and areas. However, literature in aquatic and marine applications is scarce. Hence the need to ascertain the environmental viability of natural fibre reinforced polymer composite with particular reference to the Nigerian long bamboo fibre.

\section{MATERIALS AND METHODS}

The materials used in this work included but not limited to the following; Hydrogen peroxide, concentrated acetic acid, enamel bowl, oven, ladle, bamboo chips, weighing scale, water, plastic cup, bisphenol-A-diglycidlyl ether, poly vinyl alcohol, brush, polish (gel), metal bars of $300 \mathrm{~mm} \mathrm{x}$ $3 \mathrm{~mm}$, metal sheet, tile of $300 \mathrm{~mm} \times 200 \mathrm{~mm}$ square area, weights of approximately $10 \mathrm{~kg}$, thermometer, $\mathrm{pH}$ meter and a graduated cylinder.

\section{A. Fibre Material}

Fibre is known as a supporting phase of a composite. In this investigation, bamboo fibre was considered as the supporting material for the epoxy matrix to produce the composite. Generally, bamboo can be found in most part of the world. It is a known customary and popular construction material since $\mathrm{n}$ the days of old. The scientific name of the bamboo used in this research work is called Bambusa Vulgaris [1]. It is one of the predominant varieties of bamboo found in Nigeria, West Africa and in the Western Ghats of India. This variety occupies approximately $53 \%$ of the total bamboo area in India and about $23 \%$ in Nigeria. Bamboo has high strength and is an orthotropic material. The structure of bamboo itself can be seen as a composite material, this is because it consists of long and aligned cellulose fibres immersed in a ligneous matrix of the plant [18]. The fibres were oven-dried in a controlled temperature of about $65^{\circ} \mathrm{C}$ for 6 hours to remove the moisture before the composite fabrication. The average thickness of each bamboo fibre was measured as about $1.5 \mathrm{~mm}$. Fig. 1 shows the long bamboo fibres.

In this research work, long bamboo fibres were given the place of reinforcing material in the composite. The fibres were prepared in the department of Wood Products Engineering of the Cross River University of Technology, Calabar. The moisture content of the bamboo plant used was also resolved using the gravitational method while the average moisture content was $20.5 \%$.

\section{B. Matrix Material}

Epoxy resins are mostly used in many different composites as a result of their advantages which include excellent bonding to many different fibres, good account during high temperatures and good electrical and properties. They also have low depletion values after curing and good chemical resistance. As a result of these advantages of epoxy resin over other thermoset polymers, Diglycidyl of ether Bisphenol- A- (DGEBA) was selected for use in the present research work as the matrix material [18]. 


\section{EXTRACTION OF LONG BAMBOO FIBRE}

\section{A. Maceration Method}

Before the extraction of the long bamboo fibre was carried out, a blemish free dry bamboo was cut within the Cross River University of Technology environment and the moisture content was further determined. Maceration method was used to extract the bamboo fibre used.

\section{B. Degradation of long bamboo fibre in the soil}

Long bamboo fibres were collected, weighed and buried (Fig. 1). The objective of this exercise was to determine the ability of the fibres to resist moisture even though it was intended for reinforcement purpose. The buried samples were dug out after one week and examined and buried back (Fig. 2), the observation was repeated after six weeks as shown in Fig. 3

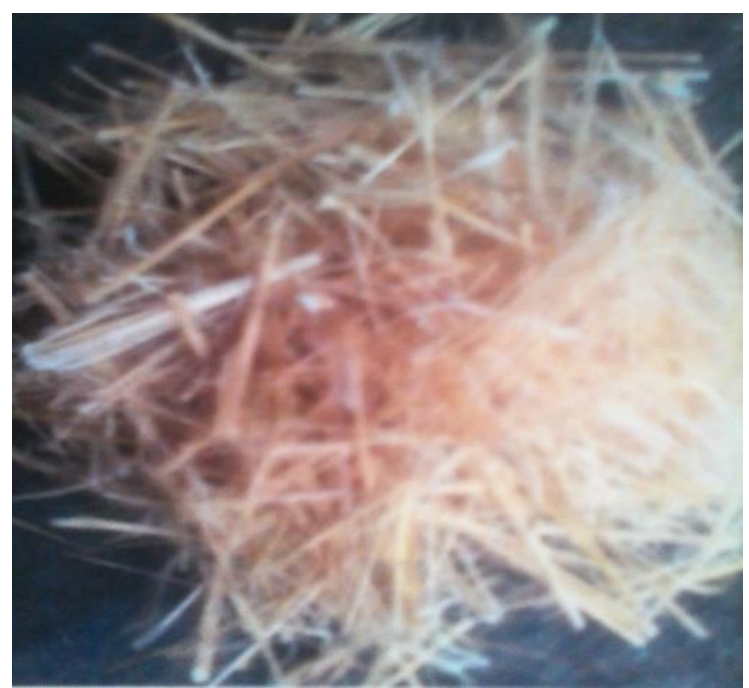

Fig. 1. Sample of Nigerian bamboo fibre before being buried

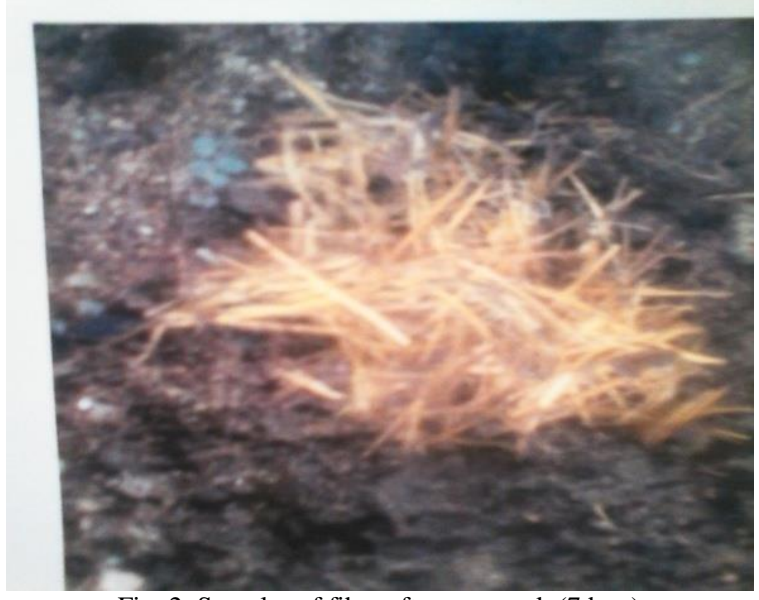

Fig. 2. Samples of fibre after one week (7days)

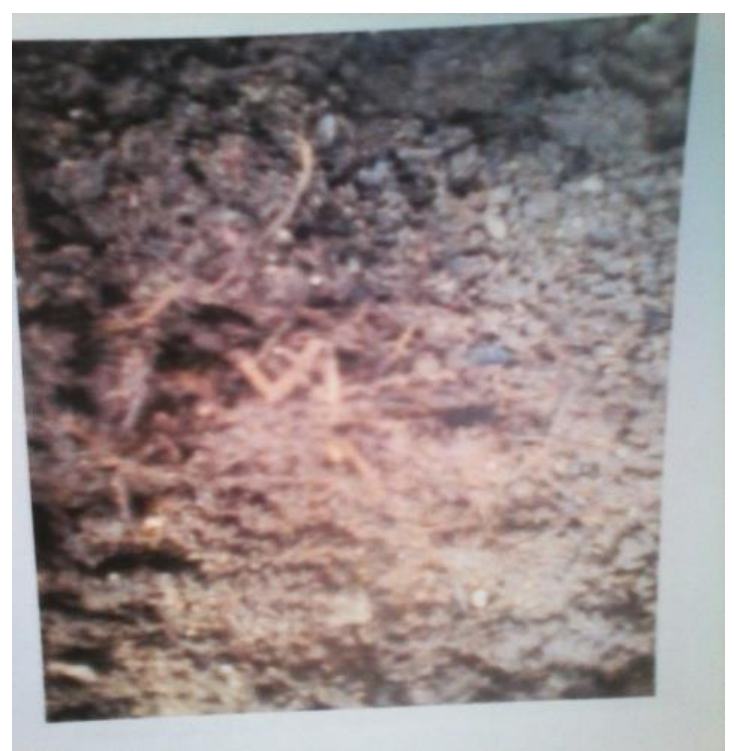

Fig.3. Samples of fibre after 42 days 6 weeks

\section{Composite Fabrication}

Different methods exist that can be used in composite fabrication, the method employed in this work was the hand lay-up method.

The resin (Bisphenol-A-diglycidyl ether) was ordered from Bristol Scientific Company Limited Lagos.

A mould of $300 \times 300 \times 3 \mathrm{~mm}$ was used. Polyvinyl alcohol and wax were used to polish the surface of the mould, they both served as releasing agents that made it easy during the removal of the mould of the composite. The resin, Bisphenol-A-diglycidyl ether(BADGE) and the hardener were measured using a beaker in a ratio of $2: 1$, that is two parts of BADGE against one part of the hardener [DER(Dow Epoxy Resin)731]. The stirring was done using a glass rod.

Part of the resin was poured into the mould and a brush was used to distribute it across the surface of the mould. The fibres were manually distributed across the mould. The resin was poured into the mould; a brush was used to push the fibres until they were saturated. The cast was post cured using a light load of $8.72 \mathrm{KN} / \mathrm{mm}^{2}$.

The mould under a closed condition was allowed to cure for 24 hours at a $25^{\circ} \mathrm{C}$ of temperature and at constant pressure. The cast product was post-cured in air for 24 hours. Samples were prepared according to ASTM standard for the environmental test. Precaution was ensured for uniformity and homogeneity of the composite because reproduction is sometimes difficult in the hand layup method that was used.

\section{Degradation of long bamboo fibre composite in the soil}

The composite fabricated was buried in the soil to determine its ability to withstand soil conditions. A cross section of the composite was cut into two different parts and buried in different holes and covered with earth. Fig. 4 shows the samples before they were buried. After one week the samples were dug out and observed (Fig. 5). This exercise was repeated for two weeks, three weeks, four weeks and nine weeks as shown in Fig. 6, 7, 8, and 9 respectively. Fig. 5b shows a short piece of the composite sample after one week of being buried. 


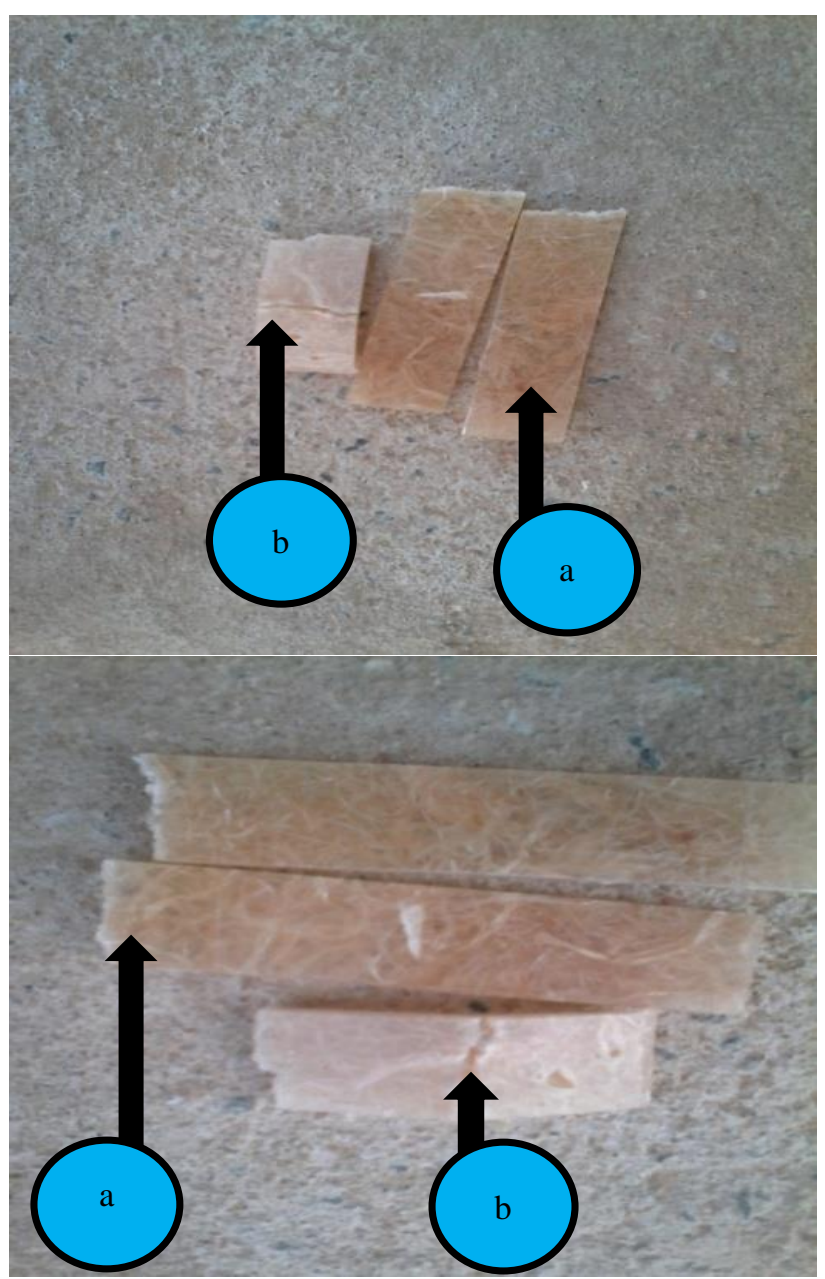

Fig. 4. Samples before being buried

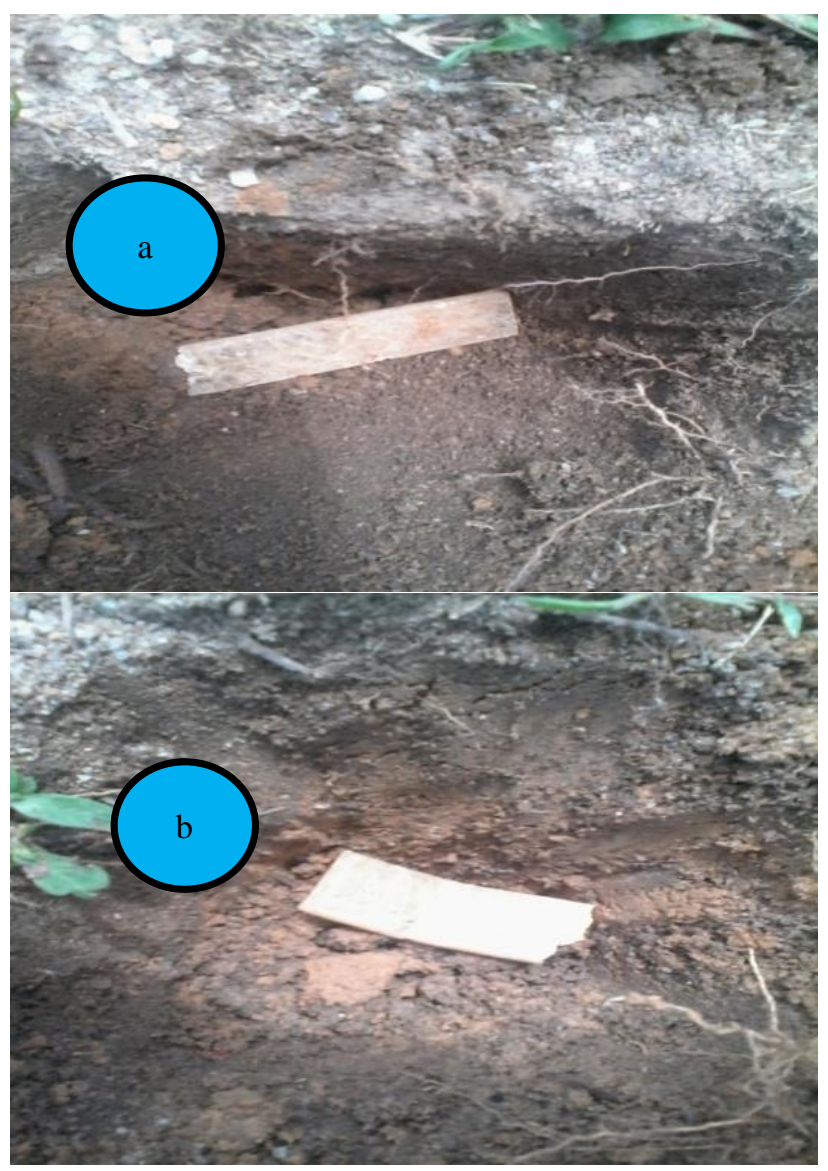

Fig. 5. Buried samples after one week

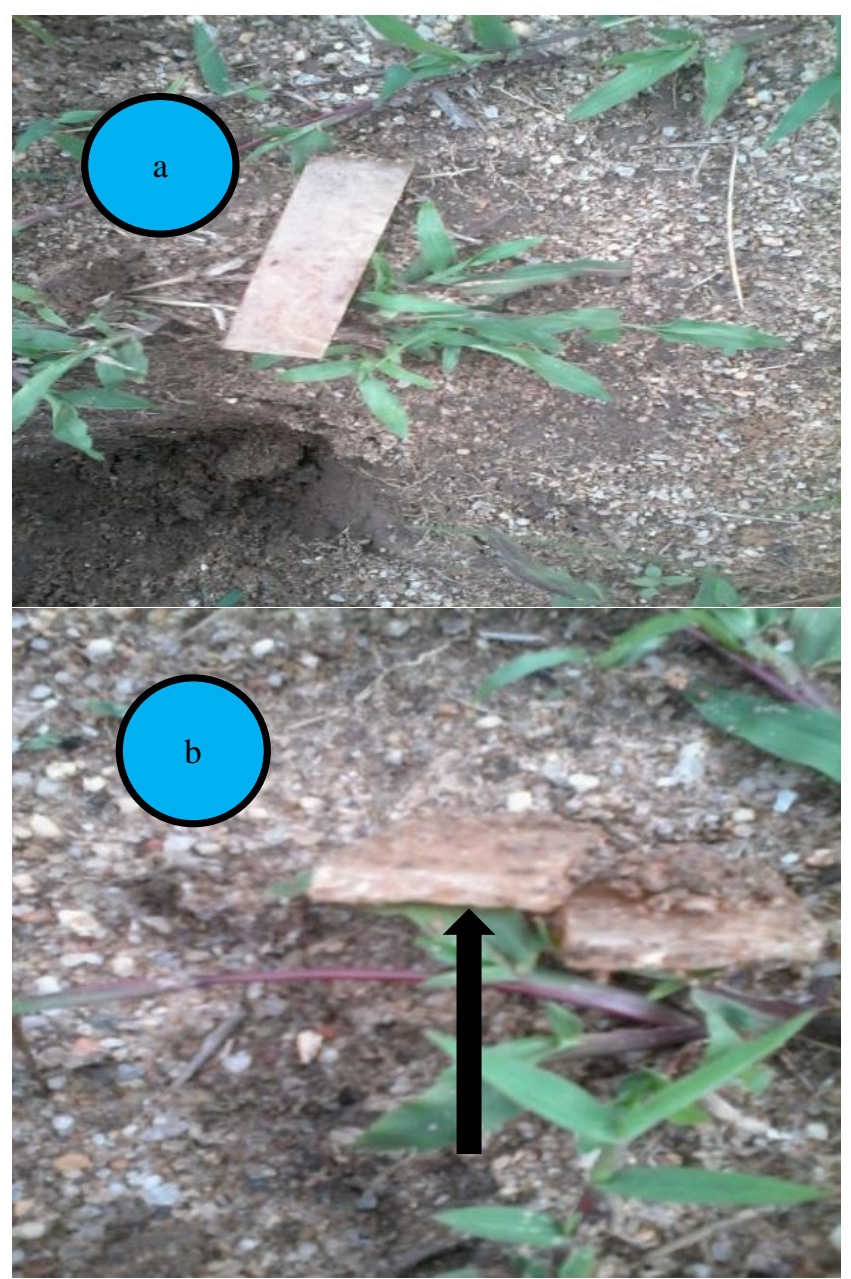

Fig. 6. Buried samples after two weeks

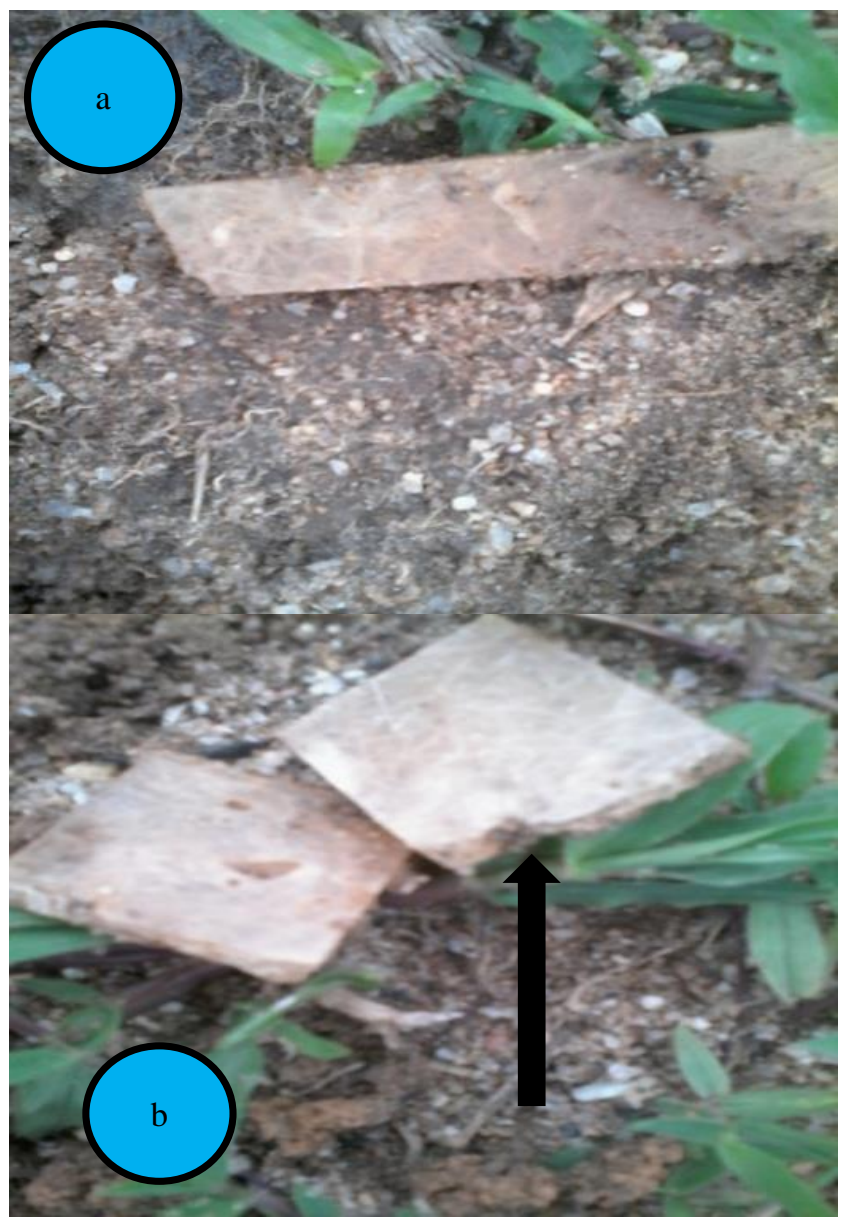

Fig. 7. Buried samples after three week 


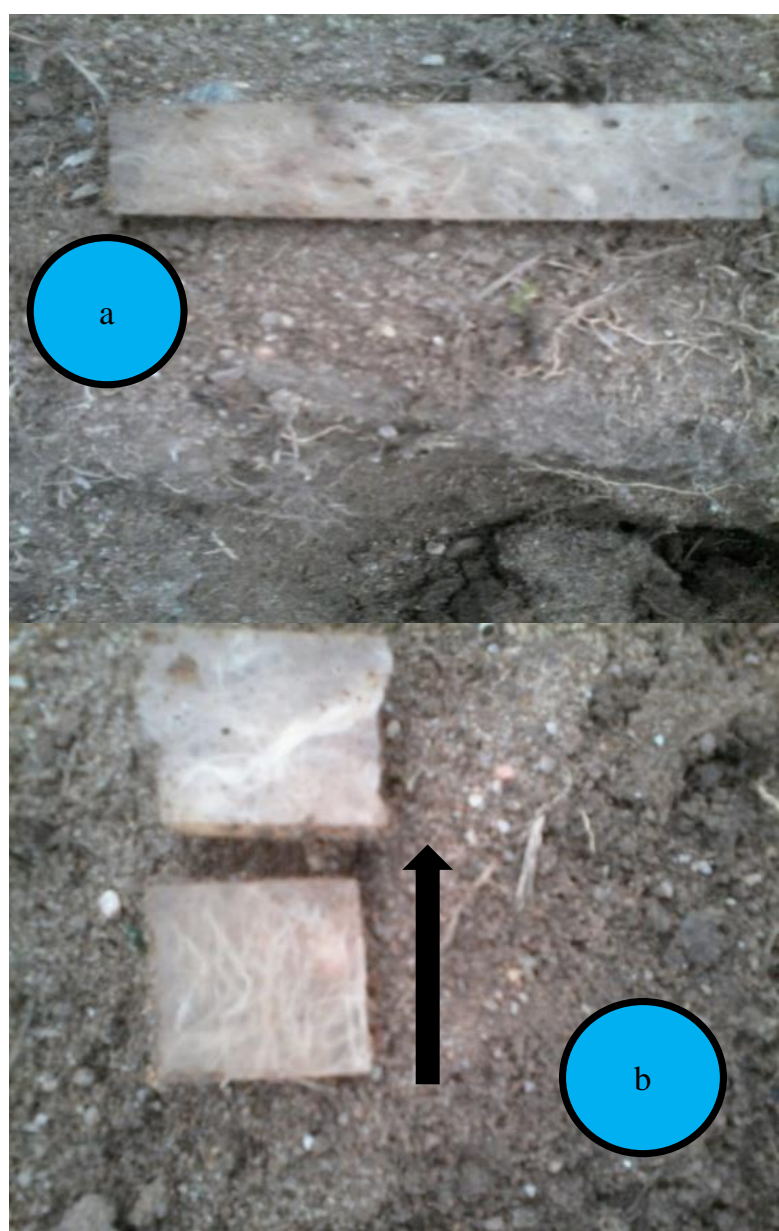

Fig. 8. Buried samples after four weeks (one month)

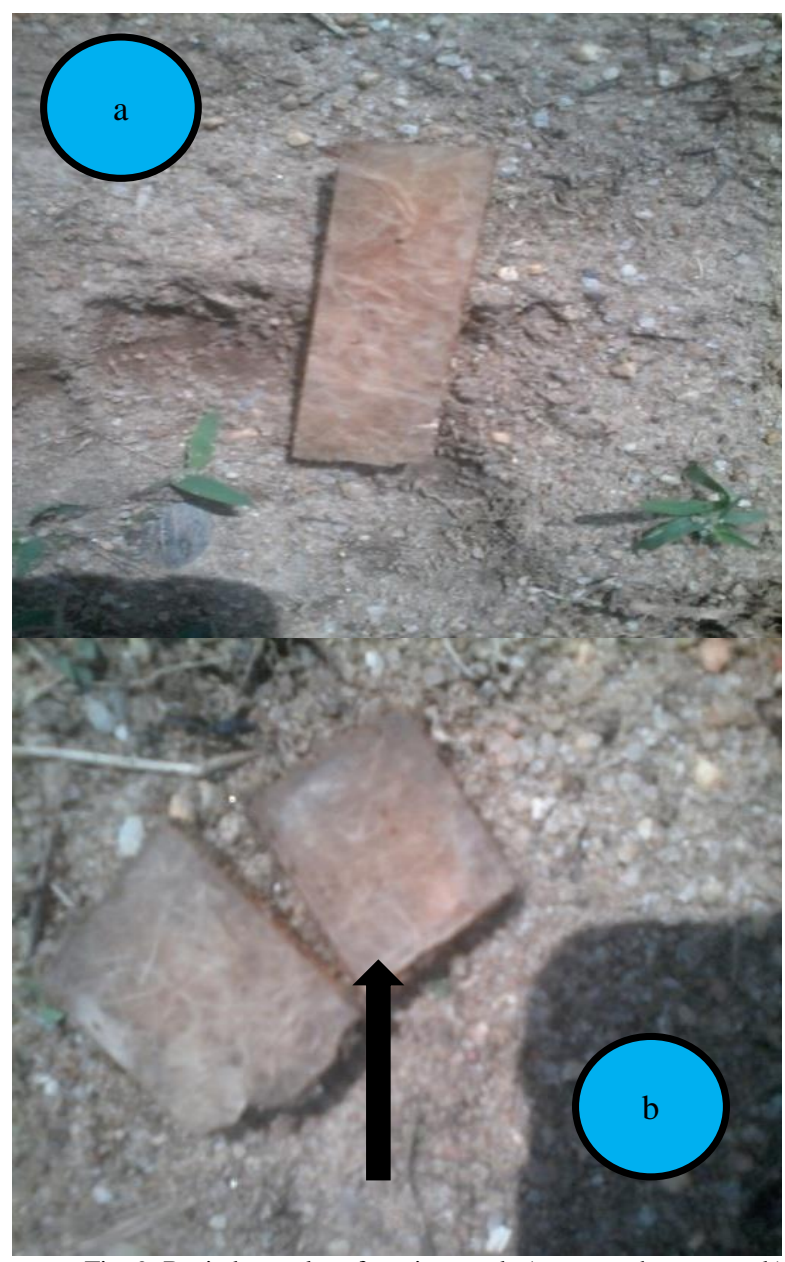

Fig. 9. Buried samples after nine weeks(two months one week)

\section{RESUlTS AND DISCUSSION}

Degradability of the Nigerian Long Bamboo Fibre: The long bamboo fibre obtained from the maceration digestion method was buried in the soil to establish the degradability and decomposition characteristics of the fibre. Fig. 1 shows the extracted long bamboo fibre before it was buried. After a period of 7 days (one week) it was observed that the fibre become moist due to the damp nature of the soil, and as shown in Fig. 2. Six weeks (42 days) later as shown in Fig. 3 there was decomposition of the fibre to the extent that only a few strands of the fibre could be seen. It showed that if more time is allowed for the fibre to remain in the soil, complete degradation and decomposition of the fibre will occur which will finally turn the fibre to form part of the soil.

Degradability of Nigerian Long Bamboo Fibre Reinforced Polymer Composite: Degradation of the long bamboo fibre reinforced composite (NLBFRPC) was studied; other works have focused on the strength of composite developed. The main objective of this aspect of the study was premised on the fact that, the development of this material must have its application not only limited to the machine tool or machine products area alone but could also be used for precast or prefabricated works, frames and other structures. This application will require the installation of these products in some environments which could be prone to pest infestation. Fig.4 to 9. showed the different characteristics of the material developed under this test. In Fig. 4, the material appears clean and reflects the original product as was developed. The materials also appeared in pieces as this was deliberate to allow the edges of the material and the reinforcement (fibre) to be exposed to the environment and the soil. Fig. 5 showed the shape and texture of the material after one week. Fig. 7 which shows the material after three weeks, the broken pieces are shown in Fig. 5b, 6b, 7b, 8b and 9b after two, three and four weeks did not show that the soil had an effect on the material, as it was observed after nine weeks there were no changes in the physical appearance of material buried. There was also no insect attack on this material after nine weeks.

\section{CONCLUSION}

The environmental degradability of long bamboo fibre reinforced polymer composite was investigated, the result shows that the composite developed and used for this work has the characteristic of resisting termites and other pest infestation when used for construction and structural materials as well as water craft components.

\section{REFERENCES}

[1] M. Ahmed, and F. A. Kamke, "Analysis of Calcutta bamboo for structural composite materials: physical and mechanical properties", wood science Technology, Vol. 39, pp. 448-459, 2005.

[2] B.D. Agarwal, and L. J. Broutman, Analysis and performance of fibre Composites. 3rd ed. New York: John Wiley \& Sons 1990 , pp.3-12.

[3] S. Biswas, and A. Satapathy, "An Assessment of Erosion Wear Response of SiC Filled Epoxy Composites Reinforced with Glass and Bamboo Fibres", International Polymer Processing, 3, 205-222, 2010.

[4] P. J. Herrera-Franco, and A. Valadez-Gonza'lez., Compos. An Appl Sci. Manuf., 35, pp. 339-345, 2004 
[5] J. Holbery, and D. Houston, "Natural-Fiber-Reinforced Polymer Composites in Automotive Applications", JOM, Vol. 58, pp. 80-,6, 2006.

[6] Luo, and A. N. Netravali, J. Mater. Sci., 34, 3709 (1999).

[7] K. Oksman, M. Skrifvars, and J. F. Selin, Compos. Sci. Tech- nol., 63, 1317, 2003.

[8] K. Okubo, and T. Fujii, Composites, 17, 21, 2002.

[9] D. Plackett, T. L. Andersen, W. B. Pedersen, and L. Nielsen, Compos. Sci. Technol., 63, 1287 (2003).

[10] R. K. Mohan, and P. A. V. Ratana, "Fabrication and Testing of natural fibre Composites: Vakka, sisal, bamboo and banana" Journal of Materials and Design, Vol. 31(1): pp. 508-513, 2010.

[11] A. K. Mohanty, A. Wibowo, M. Misra, and L. T. Drzal, Compos. An Appl. Sci. Manuf., 35, 363, 2004

[12] D. H. Mueller, and A. Krobjilowski, "New Discovery in the Properties of Composites Reinforced with Natural Fibers" Journal of Industrial Textiles, Vol. 33 pp. 111-129, 2003.

[13] T. Nishino, K. Hirao, M. Kotera, K. Nakamae, . and H. Ina- gaki, Compos. Sci. Technol., 63, 111, 2003.

[14] X.Lu, Zhang, M.O., Rong, M. Z. Yue, D.L. and G. C. Yang, "Environmental degradability of self-reinforced composites made from sisal", Composite science technology. 64.9.2004, 1301-1310.

[15] L. L. Wanjun, T. Drazal, A. K. Mohanthy, and M. Misra, "Influence of processing methods and fibre length on physical properties of kenaf fibre reinforced soy based biocomposites", Composites: Part B, Vol. 38, pp352-359, 2007.

[16] M. Wollerdorfer, and H. Bader, (1998). Ind. Crops. Prod., 8, 105

[17] R. Narayan, "Biomass (Renewable) Resources for Production of Materials, Chemicals and Fuels" - A Paradigm Shift, ACS Symp Ser 476.3, 1992

[18] D. Kishore, "A study on mechanical behaviour and damage assessment of short bamboo fibre based polymer composites", Master Degree Thesis submitted in partial fulfilment of the requirements for the degree of Master of Technology. Department of Mechanical Engineering, National Institute of Technology. Rourkela 769008 , 2011.

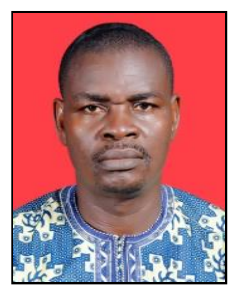

Engr. Dr F. A. Ovat was born in Cross River State Nigeria. He is a Senior Lecturer in the Department of Mechanical Engineering, Cross River University of Technology, Calabar-Nigeria. He holds a Ph.D in Mechanical Engineering (Production and Materials Engineering) from the University of Uyo, Nigeria in 2015. He is a registered member of Council for the Regulation of Engineering in Nigerian (COREN), Former Head of Department of Mechanical Engineering and currently Deputy Dean of Faculty of Engineering. He has attended National and International conferences and workshops. He is married and blessed with children. 